\title{
Vape shops: who uses them and what do they do?
}

\author{
Julie Pattinson, Sarah Lewis, Manpreet Bains, John Britton and Tessa Langley * (]
}

\begin{abstract}
Background: 'Vape shops' are a popular source for buying electronic cigarettes (e-cigarettes) and related products. The products that vape shops sell, their marketing techniques and the extent to which they provide information or encouragement to smokers to quit tobacco use, as well as the patterns of tobacco and e-cigarette use of their customers are not well understood.

Methods: We conducted cross-sectional surveys in vape shops in the East Midlands region of the United Kingdom, one with shop staff ( $n=41)$, and one with customers $(n=197)$.

Results: The majority of customers (84\%) currently used e-cigarettes. Among current vapers, $19 \%$ were dual users and $78 \%$ had quit smoking. Over half of vapers reported using a lower level of nicotine in their current e-liquid than when they started using e-cigarettes.

There was a wide variety in products and price ranges between the shops. Many staff reported that customers ask for information about quitting smoking (90\%). Less than half reported providing smoking cessation advice, although $76 \%$ of staff reported feeling confident about delivering cessation advice to customers who ask for it. Just under half of customers and shop staff said they thought it was appropriate to deliver formal in-store smoking cessation support.

Conclusions: The majority of vape shop customers are vapers who have quit smoking. Shop staff play a central role in providing customers with product information, and many provide smoking cessation advice. Further research is needed to investigate the potential for smoking cessation interventions in vape shops, including the extent to which these would appeal to non-vapers.
\end{abstract}

Keywords: E-cigarettes, Vape shops, Smoking cessation, Harm reduction

\section{Background}

Electronic cigarettes (e-cigarettes) provide a less hazardous alternative to smoked tobacco for smokers, and can aid smoking cessation [1-6]. E-cigarettes are increasingly widely used, with $20 \%$ of smokers and recent ex-smokers in England reporting use in the first quarter of 2017, compared with 3\% in 2011 [7]. E-cigarettes are now the most commonly used cessation aid in England; an estimated $34 \%$ of adults who quit or made a quit attempt in the last year reported using e-cigarettes in their most recent quit attempt, compared with $21 \%$ using over-the-counter nicotine replacement therapy and less than $3 \%$

\footnotetext{
* Correspondence: tessa.langley@nottingham.ac.uk Division of Epidemiology and Public Health, University of Nottingham, Nottingham, UK
}

receiving behavioural support [7]. The number of specialist e-cigarette shops has also increased, with recent estimates suggesting that the UK has 1700 'vape shops' [8-10]. The high street locations of vape shops make them an easily accessible option for smokers, and they are currently the most popular source for purchasing e-cigarettes in England [7].

Smokers who use vape shops are likely to be interested in temporary abstinence, cutting down or quitting smoking. Since vape shop staff have a potential major role in capitalising on opportunities to promote smoking cessation through their engagement with customers, it is important to understand the products they sell and marketing techniques they employ, and the extent to which they provide information or encouragement to smokers to quit all tobacco use. To date, the available evidence is

C The Author(s). 2018 Open Access This article is distributed under the terms of the Creative Commons Attribution 4.0 International License (http://creativecommons.org/licenses/by/4.0/), which permits unrestricted use, distribution, and reproduction in any medium, provided you give appropriate credit to the original author(s) and the source, provide a link to the Creative Commons license, and indicate if changes were made. The Creative Commons Public Domain Dedication waiver (http://creativecommons.org/publicdomain/zero/1.0/) applies to the data made available in this article, unless otherwise stated. 
limited to studies of vape shops in the USA, and one qualitative study in the UK [11-26]. While anecdotal reports suggest that some UK shops offer services such as smoking cessation advice and receive referrals from local health services, there are no quantitative studies of these or other vape shop functions and activities in the UK. We now report cross-sectional surveys of the products and services, including smoking cessation advice, offered in vape shops in the East Midlands region of the UK, and of the patterns of tobacco and e-cigarette use and sociodemographic characteristics of their customers.

\section{Methods}

\section{Study population}

The study population included shop staff (including owners and managers) and customers in vape shops across three counties in the East Midlands region (Nottinghamshire, Lincolnshire and Leicestershire). Eligible participants were 18 years of age or older and were able to give informed consent. Using an online UK e-cigarette shop directory we identified 97 e-cigarette shops across the three counties [27]. We estimated that a sample of 59 would provide estimates of proportions (for example of shops providing cessation advice) to within $13 \%$. We identified a random sample of 65 of the shops, stratified by county and urban or rural location, using the random sampling option in Stata 14. Our sample allowed for a $10 \%$ refusal rate.

\section{Data collection}

\section{Staff survey}

Shop staff were contacted by telephone to seek their agreement for a researcher to visit their shop to collect data. Visits were undertaken on a mixture of weekdays and weekends to maximise the representativeness of the customer sample. Shop questionnaires were completed over the phone or face-to-face. All data were collected between January and April 2016.

The staff questionnaire comprised 36 questions and asked about the types of products available and product prices and promotions. The questionnaire also explored the shops' role in smoking cessation, such as whether customers seek advice about quitting smoking in shops, whether shops provide information about quitting, whether vape shops are an appropriate environment in which to offer smoking cessation advice and how this should be implemented (for example, by a trained member of shop staff or an external trained advisor).

\section{Customer survey}

As not all shop staff were willing to allow the study researcher to approach customers directly, customer data were collected in two ways. In shops which permitted a direct approach, the researcher approached all customers entering the shop during the visit, explained the background to the study and asked if they would like to participate. Customers who agreed to take part completed the questionnaire face-to-face with the researcher. In shops which did not allow customers to be approached directly, the researcher left printed copies of the questionnaire for customers to complete and to be collected from the shop at a later date.

The customer questionnaire comprised 41 questions and assessed socio-demographic characteristics, patterns of e-cigarette and tobacco use, motivation for using ecigarettes, preferences for type of e-cigarettes product, their use in smoking cessation and risk perceptions. Customers' views about e-cigarette shops were also explored. Questions on tobacco use and previous quit attempts were obtained from the Smoking Tool Kit Study [2], and sociodemographic questions from the General Lifestyle Survey [3] and the Integrated Household Survey [4]. Customers who completed the survey were offered the opportunity to be entered into a prize draw to win to win $£ 200, £ 100$ or $£ 50$.

\section{Piloting}

The staff questionnaire was piloted in five shops. The customer questionnaire was piloted in members of the UK Centre for Tobacco and Alcohol Studies' public involvement group, a group of Nottingham-based smokers, ex-smokers and e-cigarette users. Both questionnaires are available in online supplementary material (Additional files 1 and 2).

\section{Statistical analysis}

All data were inputted in Excel and exported into SPSS-22 for data management and statistical analysis. Descriptive analysis was used to explore key aspects of the data. Because some of the data were obtained via self-completion and some face-to-face respondents said they had insufficient time to complete the full questionnaire, there were some missing data. These are reported in a 'no response' category.

\section{Results}

Vape shop staff survey

Staff in $41(63 \%)$ shops agreed to participate in staff surveys, and 36 of these also agreed to allow customer interviews. The shops that declined to take part tended to be small independent shops, and in most cases did so because they were concerned that their customers would not want to be asked to complete a survey. 14 of the staff respondents were shop owners, 17 were managers and 10 were other staff members. 


\section{Types of e-cigarette products available}

All shops stocked starter kits (which typically include a device and a bottle of e-liquid), e-liquids, atomisers, batteries and accessories (Table 1). Nicotine strengths of e-liquids ranged from 0 to $36 \mathrm{mg} / \mathrm{ml}$. All shops stocked a $0 \mathrm{mg} / \mathrm{ml}$ nicotine e-liquid, and over half (54\%) stocked $24 \mathrm{mg} / \mathrm{ml}$ liquids; $10 \%$ stocked liquids containing up to $36 \mathrm{mg} / \mathrm{ml}$. In $17 \%$ of shops the highest nicotine concentration was $18 \mathrm{mg} / \mathrm{ml}$, and in a further $17 \%$ it was $20 \mathrm{mg} / \mathrm{ml}$.

The most commonly stocked sizes of e-liquid bottle were $10 \mathrm{ml}(100 \%)$ and $30 \mathrm{ml}(100 \%)$. Every shop stocked menthol, tobacco and fruit e-liquid flavours. $63 \%$ of shops reported stocking other flavours; among those who specified these flavours, dessert-based flavours were the most common. The majority of staff (78\%) reported that the fruit flavours were the most popular among their customers.

\section{Price and promotions}

There was a wide variety in price ranges between shops. In $46 \%$ of shops starter kits ranged from $£ 10-£ 20$, and in $37 \%$ they cost $£ 21-£ 30$ (Table 1). Promotions included discounts and free trials of starter kits. The prices of e-liquids did not increase with nicotine strength in any of the shops.

\section{Smoking cessation advice and types of services available}

A large proportion of staff respondents reported that customers asked for information about quitting smoking (90\%; Table 2). Less than half (41\%) reported providing any sort of smoking cessation advice, although $76 \%$ of staff reported feeling quite or very confident about delivering cessation advice to customers who ask for it. The majority of shops offered information about the products (93\%) and cutting down on smoking (88\%). Staff reported providing other information, including battery safety, operation and maintenance. The majority of staff accessed the information they gave to customers online and/or provided information based on their personal experiences.

Just under half of staff respondents thought it was a good idea to deliver smoking cessation advice from a trained individual in their shops; a similar proportion were unsure. Among those who felt it was a good idea, 74\% thought the best way to deliver it would be through support from a trained existing member of staff (Table 2).

\section{Vape shop customer survey}

The customer survey was completed by 197 customers, either by self completion (83 responses) or face-to-face interview (114 responses).
Table 1 Vape shop products, prices and promotions

\begin{tabular}{|c|c|}
\hline Question & $n(\%)$ \\
\hline \multicolumn{2}{|c|}{ Highest nicotine content liquid (mg/ml) } \\
\hline 0 & $1(2)$ \\
\hline 18 & $7(17)$ \\
\hline 20 & $7(17)$ \\
\hline 24 & $22(54)$ \\
\hline 36 & $4(10)$ \\
\hline \multicolumn{2}{|c|}{ E-liquid bottle sizes stocked ( $\mathrm{ml}$, multiple responses permitted) } \\
\hline $1-2^{*}$ & $19(46)$ \\
\hline 10 & $41(100)$ \\
\hline 15 & $8(20)$ \\
\hline 30 & $41(100)$ \\
\hline $50-60$ & $9(22)$ \\
\hline $100-200$ & $7(17)$ \\
\hline \multicolumn{2}{|c|}{ Flavours stocked (multiple responses permitted) } \\
\hline Fruit & $41(100)$ \\
\hline Tobacco & $41(100)$ \\
\hline Menthol & $41(100)$ \\
\hline Other & $26(63)$ \\
\hline \multicolumn{2}{|c|}{ Most popular flavours (multiple responses permitted) } \\
\hline Fruit & $32(78)$ \\
\hline Tobacco & $20(49)$ \\
\hline Menthol & $27(66)$ \\
\hline Other & $7(17)$ \\
\hline \multicolumn{2}{|c|}{ Cheapest starter kit price $(£)$} \\
\hline$\leq 10$ & $4(10)$ \\
\hline 10-19.99 & $19(46)$ \\
\hline $20-29.99$ & $15(37)$ \\
\hline$\geq 30$ & $2(5)$ \\
\hline No response & $1(2)$ \\
\hline \multicolumn{2}{|c|}{ Most expensive starter kit price $(£)$} \\
\hline$\leq 10$ & $0(0)$ \\
\hline 10-19.99 & $3(7)$ \\
\hline $20-29.99$ & $3(7)$ \\
\hline $30-49.99$ & $6(15)$ \\
\hline 50-99.99 & $17(41)$ \\
\hline$\geq 100$ & $10(24)$ \\
\hline No response & $2(5)$ \\
\hline \multicolumn{2}{|c|}{ Promotions (multiple responses permitted) } \\
\hline None & $2(5)$ \\
\hline Buy one get one free & $5(12)$ \\
\hline Discounts & $22(54)$ \\
\hline Free trials & $5(12)$ \\
\hline Other & $23(56)$ \\
\hline
\end{tabular}

Note: Percentages are rounded to the nearest whole number*E-liquid bottles usually start at $10 \mathrm{ml}$ - respondents reporting this size are likely to be referring to prefilled cartridges 
Table 2 Information and support provided by vape shops $(n=41)$

\begin{tabular}{lc}
\hline Question & $n(\%)$ \\
\hline Do customers talk about experiences of trying to quit smoking? \\
Yes many do & $30(73)$ \\
Yes some do & $9(22)$ \\
No & $1(2)$ \\
No response & $1(2)$ \\
Do customers ask for advice about quitting? & $37(90)$ \\
Yes & $3(7)$ \\
No & $1(2)$ \\
No response &
\end{tabular}

What kind of information do you give to customers? (multiple responses permitted)

$\begin{array}{ll}\text { Product information } & 38(93) \\ \text { Smoking cessation advice } & 17(41) \\ \text { Information how to cut down regular cigarettes } & 36(88) \\ \text { Other } & 9(22) \\ \text { Where do you access this information? (Open question) } & \\ \text { Online } & 22(54) \\ \text { In-house training } & 6(15) \\ \text { Personal experience } & 10(24) \\ \text { Manufacturers' guidelines } & 3(7)\end{array}$

How confident are you about offering smoking cessation advice to customers that ask for it?

$\begin{array}{ll}\text { Not at all } & 0(0) \\ \text { Not too confident } & 2(5) \\ \text { Quite confident } & 15(37) \\ \text { Very confident } & 16(39) \\ \text { No response } & 8(20)\end{array}$

Do you think it would be a good idea to deliver smoking cessation advice with training in your shop?

$\begin{array}{ll}\text { Yes } & 19(46) \\ \text { No } & 4(10) \\ \text { Not sure } & 17(41) \\ \text { No response } & 1(2)\end{array}$

Do you think customers would be interested in accessing this in-store smoking cessation service?

$\begin{array}{ll}\text { Yes } & 17(41) \\ \text { No } & 9(22) \\ \text { Not sure } & 15(37)\end{array}$

Which type of in-store cessation service do you think might work best? ( $n=19$ - staff who think service is a good idea)

$\begin{array}{ll}\text { Support from a training member of staff } & 14(74) \\ \text { Face-to-face support from an external advisor } & 1(5) \\ \text { A text or email-based support service } & 0(0) \\ \text { No response } & 4(21)\end{array}$

Note: Percentages are rounded to the nearest whole number

\section{Demographic characteristics and e-cigarette use}

The majority of customer participants were male, white British, aged between 18 and 39 years, in full time employment and held a formal qualification (Table 3).

The majority of participating customers (84\%) currently used e-cigarettes (Table 4 ). Of the $16 \%$ that did not, half $(8 \%)$ were considering using an e-cigarette, a quarter (4\%) were purchasing for somebody else and a further quarter (4\%) were collecting information only.

Table 3 Participants Demographic Characteristics $(n=197)$

\begin{tabular}{|c|c|}
\hline Question & $n(\%)$ \\
\hline \multicolumn{2}{|l|}{ Sex } \\
\hline Male & $113(57)$ \\
\hline Female & $80(41)$ \\
\hline No response & $4(2)$ \\
\hline \multicolumn{2}{|l|}{ Age } \\
\hline $18-25$ & $50(25)$ \\
\hline $26-30$ & $43(22)$ \\
\hline $31-39$ & $35(18)$ \\
\hline $40-49$ & $24(12)$ \\
\hline $50-59$ & $17(9)$ \\
\hline $60+$ & $23(12)$ \\
\hline No response & $5(3)$ \\
\hline \multicolumn{2}{|l|}{ Ethnic group } \\
\hline White & $167(85)$ \\
\hline Mixed/multiple ethnic group & $4(2)$ \\
\hline Asian/Asian British & $15(8)$ \\
\hline Black African Caribbean/black British & $2(1)$ \\
\hline Other ethnic group & $1(1)$ \\
\hline No response & $8(4)$ \\
\hline \multicolumn{2}{|l|}{ Education } \\
\hline Degree level or equivalent & $26(13)$ \\
\hline A Level, equivalent or higher education below degree level ${ }^{a}$ & $53(27)$ \\
\hline GCSE or equivalent ${ }^{a}$ & $52(26)$ \\
\hline Other below degree level & $5(3)$ \\
\hline No formal qualifications & $40(20)$ \\
\hline No response & $21(11)$ \\
\hline \multicolumn{2}{|l|}{ Employment } \\
\hline In full time work & $111(56)$ \\
\hline In part time work & $30(15)$ \\
\hline Retired & $18(9)$ \\
\hline Student & $12(6)$ \\
\hline $\begin{array}{l}\text { Not in work (long term sick, disabled, unemployed, } \\
\text { other reason) }\end{array}$ & $19(10)$ \\
\hline No response & $7(4)$ \\
\hline
\end{tabular}

Note: Percentages are rounded to the nearest whole number ${ }^{a}$ GCSEs and A-levels are secondary school leaving qualifications in the UK. GCSEs are typically taken at age 16 , A-levels at age 18 
Table 4 Tobacco use, e-cigarette use and smoking cessation

Question
All participants ( $n=197$ )
Reason for vape shop visit
I am currently using e-cigarettes
I am considering using e-cigarettes
I am purchasing e-cigarettes for somebody else
I am visiting to collect information
Other
All e-cigarette users ( $n=165$ )
Tobacco and e-cigarette use
I currently use both e-cigarettes and regular cigarettes
I currently use e-cigarettes only but used to smoke
regular cigarettes
I currently use e-cigarettes but have never smoked
regular cigarettes
No response
Time since starting e-cigarette use
Less than $24 \mathrm{~h}$
Between 1 day and 1 week
Between 1 week and 4 weeks
Between 1 month and 1 year
Between 1 year and 2 years
Longer than 2 years
Don't know/other

$1(1)$

$1(1)$
Table 4 Tobacco use, e-cigarette use and smoking cessation (Continued)

$n(\%)$

$165(84)$

47 (28)

56 (34)

$41(25)$

Reasons for starting to use an e-cigarette (multiple responses permitted)

Wanted to quit smoking

Previous unsuccessful attempt

Reduce number I smoke

Friends/family

129 (78)

$33(20)$

$26(16)$

$40(24)$

Flavours I like

$24(15)$

Advert

Can use e-cigarette where can't smoke

$1(1)$

29 (18)

55 (33)

E-cigarettes are less harmful

Cheaper than regular tobacco

Curiosity

$53(32)$

$24(15)$

Other

$7(4)$

Main reason for using an e-cigarette

To help me quit/stay quit

$117(71)$

To reduce number of regular cigarettes I smoke

I can use e-cigarettes where I can't smoke

$17(10)$

$6(4)$

Other

No response

$13(8)$

Perceived harm of using e-cigarette

More harmful than tobacco cigarettes

Less harmful than tobacco cigarettes

The same as tobacco cigarettes
Question

\begin{tabular}{ll} 
Question & $n(\%)$ \\
\hline Don't know & $17(10)$ \\
No response & $7(4)$ \\
Side effects while using e-cigarette & \\
$\quad$ No side effects & $120(73)$ \\
Side effects & $45(27)$ \\
Weekly spend on e-cigarettes & \\
$<5 £$ & $38(23)$ \\
$£ 5-10$ & $63(38)$ \\
$£ 11-20$ & $33(20)$ \\
$£ 21-30$ & $13(8)$ \\
Other & $7(4)$ \\
Don't know & $3(2)$ \\
No response & $8(5)$
\end{tabular}

Nicotine content used when started vaping $(\mathrm{mg} / \mathrm{ml})$

0

$3(2)$

$1-3$

$4-10$

5 (3)

$11-20$

$16(10)$

$74(45)$

$>20$

$43(26)$

No response

24 (15)

Nicotine concentration currently used ( $\mathrm{mg} / \mathrm{ml}$ )

0

$1-3$

$52(32)$

$4-10$

$41(25)$

$11-20$

$33(20)$

$>20$

No response

17 (10)

Change in nicotine content since started vaping

Reduced

$92(56)$

Stayed the same

$41(25)$

Increased

$0(0)$

No response

$32(19)$

Preferred e-liquid flavour

Fruit

Tobacco

Menthol

21 (13)

Other

No response

Where usually buy e-cigarettes or liquids

From a shop

Online

Both

35 (21) 
Table 4 Tobacco use, e-cigarette use and smoking cessation (Continued)

\begin{tabular}{cc}
\hline Question & $n(\%)$ \\
\hline Other & $2(1)$ \\
No response & $9(5)$
\end{tabular}

Type of information/advice received from shop (multiple responses permitted)

$\begin{array}{ll}\text { About the products } & 148(90) \\ \text { About stopping smoking tobacco cigarettes } & 62(38) \\ \text { About how to cut down on smoking tobacco cigarettes } & 46(28) \\ \text { Other } & 2(1)\end{array}$

Appropriate to deliver advice on quitting smoking in an e-cigarette shop?

$\begin{array}{ll}\text { Yes and I would consider using it } & 75(45) \\ \text { Yes but I would not consider using it } & 5(3) \\ \text { Maybe } & 40(27) \\ \text { Not sure } & 15(9) \\ \text { No } & 10(6) \\ \text { Don't want to answer } & 5(3) \\ \text { No response } & 15(9)\end{array}$

Best way to deliver in-shop service ( $n=75$ - vapers who would consider using service)

Support from a trained member of staff

Face-to-face support from an external advisor

A text or email-based support service

Other

No response

Ex-smokers only $(n=128)$

Time since quit smoking

Within the last week

Within the last month

Within the last 6 months

Within the last year

Over a year ago

No response

2 (2)

Methods used to help stop smoking during the most recent serious quit attempt (multiple responses permitted)

Electronic cigarette

Nicotine replacement therapy

Nicotine replacement on prescription

Zyban

Champix

Stop smoking group

Smoking helpline

NHS smoke free website

App

Hypnotherapy

Acupuncture
Table 4 Tobacco use, e-cigarette use and smoking cessation (Continued)

\begin{tabular}{ll}
\hline Question & $n(\%)$ \\
\hline Booklet & $1(1)$ \\
Don't know & $9(7)$ \\
Other & $2(2)$
\end{tabular}

Note: Percentages are rounded to the nearest whole number

Among participants currently using an e-cigarette, 19\% were dual users (e-cigarettes and regular cigarettes) and $78 \%$ had quit smoking cigarettes. A minority (3\%) of those using e-cigarettes had never smoked cigarettes.

The main reasons reported for taking up vaping were wanting to quit smoking, the belief that vaping is less harmful than smoking, and e-cigarettes being cheaper than regular tobacco. The majority of e-cigarette users, $86 \%$, perceived EC to be less harmful than regular cigarettes, and $82 \%$ had experienced no side effects from vaping. Among those who had, the side effects headaches, chest pain/shortness of breath, coughs and colds and dry mouth/throat were the most frequently reported. Most vapers (64\%) reported spending up to $£ 10$ a week on e-cigarettes.

More than half of participants reported using a lower level of nicotine in their current e-liquid than when they first started using an e-cigarette (Table 4). The majority (57\%) reported currently using an e-liquid containing $1-10 \mathrm{mg} / \mathrm{ml}$, and a small proportion used zero nicotine liquids.

\section{Ex-smokers}

The majority of ex-smokers reported having quit more than one year ago (59\%). Health concerns and the costs of smoking were frequently cited reasons for quitting. Most (89\%) had used an e-cigarette to help them quit, but two in five had also used nicotine replacement therapy.

\section{Dual users}

There was a small proportion of dual users in the sample $(n=31,19 \%) .65 \%$ of dual users reported smoking tobacco cigarettes every day, while $61 \%$ also reported smoking a tobacco cigarette within the last $24 \mathrm{~h}$. However, $58 \%$ intended to give up tobacco smoking within the next 6 months. Half of dual users stated their most recent quit attempt was expense-related (52\%) and due to a future health concern (45\%). (Data not shown).

\section{Vape shop experiences and smoking cessation services} Nearly three quarters of participants who reported vaping (71\%) said they usually buy their vaping products from a shop. Most participants reported receiving information about the products from the shop they were in. Around two in five said they received information on 
quitting and just over a quarter received information about cutting down. Just under half (45\%) stated that they thought it was appropriate to deliver smoking cessation advice and support in the shop and that they would consider using such support; of these, three quarters felt that the best way to deliver such a service was through a trained member of staff.

\section{Discussion}

This study found that vape shops cater for customers seeking a wide range of nicotine content, flavours and price points, and offer a variety of promotions. Most vape shop customers were current vapers who had quit smoking, and were using an e-cigarette to either quit or stay quit. A very small minority were vapers who had never smoked. The majority of customers had reduced the nicotine content of their e-liquid since taking up vaping. Shop staff reported that most customers ask for advice about quitting smoking, but that most of the information they provided was about the products they sell. There were mixed views among both staff and customers as to whether it would be appropriate to deliver smoking cessation advice in-store; however there was broad consensus that if such support were to be delivered, support from a trained member of existing staff would be preferred.

Our study has a number of strengths and limitations. Most existing vape shop studies have used qualitative techniques; by using a survey we were able to quantify key characteristics in our population, such as dual use, albeit that we were not able to analyse smoking/vaping trajectories over time. Nevertheless, some aspects, such as understanding the type and accuracy of advice given to customers, would have benefitted from qualitative interviews with shop staff.

While we only used one directory to identify shops, the use of a large vape shop-specific directory rather than a generic business directory (e.g. Yell) means that we are likely to have identified the majority of shops in our study area. Recruitment to the study was more challenging than anticipated; we approached 65 shops, but only 41 agreed to take part. While the sample size of both surveys is therefore relatively small, and prevents us from reliably analysing subgroups (e.g. new vs. longterm vapers), our findings provide an initial insight into who accesses vape shops and why, the products and services offered and the potential for capitalising on opportunities to promote smoking cessation in the vape shop setting. We used a systematic approach to identify vape shops in the East Midlands region, and a sampling strategy which maximises the representativeness of our sample. The study was conducted in a limited geographic region; however we sampled shops in both urban and rural areas to maximise the representativeness of our sample. Our study was conducted prior to the implementation of the EU Tobacco Products Directive, which imposed limits on nicotine strength $(20 \mathrm{mg} / \mathrm{ml})$ and e-liquid bottle sizes $(10 \mathrm{ml})$ in the $\mathrm{EU}$ [28]; the typical nicotine concentration and bottles sizes will therefore have changed in UK vape shops since our study was conducted.

Our pragmatic approach to data collection means that our customer sample is not random. Some respondents, particularly customers, often lacked the time to fully complete the survey resulting in some missing data. Furthermore, we found that the vape shop setting made it impractical to collect carbon monoxide readings to confirm smoking status, and this measure is therefore based on self-report. There is a risk of social desirability bias whereby respondents are more likely say they have quit smoking cigarettes because they are in a vape shop; however, in existing research biochemical validation found that the vast majority of self-reported quitters in vape shops had indeed quit [25]. Our combination of face-to-face interviews and allowing customers to complete questionnaire in their own time is likely to have maximised the amount and quality of data collected.

Our finding that the majority of vape shop customers were ex-smokers and used e-cigarettes to stop smoking or stay quit conflicts somewhat with population-level data suggesting that around half of adults who use ecigarettes are dual users $[7,29]$. It seems likely that vapers who use specialist vape shops are not representative of vapers in general, and may represent a group more committed to vaping (and hence more likely to have quit smoking) than casual purchasers of ecigarettes from convenience stores and supermarkets. While we are unable to draw any causal links between this population's e-cigarette use and quitting smoking, our findings underline that many vapers are successful quitters. Furthermore, our study found that the majority of ex-smokers had quit smoking more than a year ago, suggesting that e-cigarettes may help in sustained as well as in initial cessation. While there is limited evidence as to the effectiveness of e-cigarettes for quitting when bought in vape shops, one pilot study found that at 12 month follow-up, $40 \%$ of smokers making their first purchase at a vape shop had quit smoking [16].

Around two thirds of vapers in our sample reported having cut down their nicotine concentration in their eliquid since taking up smoking; this is consistent with a previous study conducted in the US [20]. This finding may reflect improvements in the ability of e-cigarette devices to deliver nicotine [25]; however, the level by which customers report cutting down (an average of $13 \mathrm{mg} / \mathrm{ml}$ among those reducing) suggests that e-cigarettes may enable a two-stage quitting process whereby smokers reduce or overcome their nicotine addiction before 
attempting to end the habitual behaviours involved and associated with smoking. However, while the majority of our sample used a relatively low nicotine concentration when they started vaping, over a quarter reported using an e-liquid containing a level of nicotine exceeding restrictions imposed by the new EU Tobacco Products Directive $(20 \mathrm{mg} / \mathrm{ml})$ [28]. This raises concerns that at least some potential vapers will be put off by fears that e-cigarettes will, at least at the outset, provide insufficient levels of nicotine.

Many customer survey respondents reported cost as a factor which influenced their decision to use e-cigarettes, and most reported a weekly spend of less than $£ 10$, i.e. less than the cost of a single pack of 20 premium cigarettes. Existing evidence suggests that $1 \mathrm{ml}$ of e-liquid is consumed over a length of time equal to that which in which a typical smoker consumes 5.63 combustible cigarettes [30]. Based on this assumption, a starter kit costing $£ 20$ containing $10 \mathrm{ml}$ of e-liquid would provide the equivalent of 56 cigarettes (2.8 packs of 20). The weighted average price for 20 cigarettes in the UK is currently $£ 7.8$ [31] - this suggests that, in the UK, where the price of combustible tobacco is high, the start-up cost of vaping may be similar to the cost of (licit) tobacco; the cost of ongoing e-cigarette use is likely to be lower. Furthermore, we found that shops frequently run promotions, which is likely to help keep the cost down. Smoking imposes a substantial financial burden on smokers, a high proportion of whom are already living on low incomes [32]. The lower cost of e-cigarettes and the price-based marketing approaches used by vape shop customers are therefore encouraging, as they highlight the potential of e-cigarettes as not only a less harmful but also a cheaper alternative to smoking. Existing evidence suggests that in England, vapers are more likely to be from high socioeconomic groups [7]. Ensuring that deprived smokers are informed of the financial benefits, as well as potential health benefits of switching to e-cigarettes may be a way of encouraging use in this population.

Our findings support existing evidence that e-cigarette users are more likely to have accurate perceptions of harm of vaping than the general population or smokers who do not vape; nearly all our customers respondents (82\%) believed vaping to be less harmful than tobacco smoking [29]. Given that role that vape shop staff are likely to play in influencing vapers' and potential vapers' perceptions of harm and other aspects of vaping (such as effectiveness for smoking cessation), it is essential that they look to accurate and up-to-date sources of information about e-cigarettes. However, previous research suggests that information conveyed to vape shop customers may be incomplete or misinterpreted [13]. Our findings that staff access information in a wide range of ways, including online and based on personal experience, suggests there is a risk that staff may provide inaccurate or biased information. Future research should consider ways to ensure that vape shop customers, particularly those considering vaping for the first time, are given upto-date evidence-based information.

While the majority of shop staff said customers ask for advice about quitting smoking and felt confident about giving such advice, less than half said they actually provide it. It is not clear whether this means that staff sometimes avoid giving advice, preferring, for example, to refer customers to a health professional; and if so, why this may be. Detailed data on the nature of advice given were not collected, and future research should seek to better understand the types of information customers receive, how that information is interpreted, and whether it is acted upon; however, the most frequent response to an open-ended question about the type of cessation advice given was 'non-medical advice' ( $n=17)$, suggesting that shop staff may be unwilling to give clinical cessation advice. However, nine in ten staff said that they provide advice on cutting down regular cigarettes. Taken together, these findings indicate that smoking cessation and reduction are part of the dialogue between vape shop staff and customers, and suggests that there is scope for increasing the level of information vape shop customers receive about quitting using ecigarettes.

There were mixed views about whether delivering formal smoking cessation advice in shops was a good idea. This may reflect existing evidence which suggests that to some e-cigarette users pleasure and enjoyment are central to the vaping experience, while others regard e-cigarettes as a medical treatment for nicotine addiction, with enjoyment and culture playing much less of a role [33]. A recent vape shop study by Ward et al. identified a divide between groups of e-cigarette users, with some liking the non-medicalised environment of vape shops, but others, who perceive ecigarettes as a medical treatment, sometimes being intimidated by the vape shop setting. It has been suggested that providing 'recreational' and medical pathways to e-cigarette use may maximise the potential for harm reduction [33, 34], and Ward et al. suggest that informal co-working between shops and stop smoking services' could encourage smokers who are unsure about e-cigarettes [26]. Our mixed findings indicate that achieving this successfully within the vape shop setting might be challenging, given the need to appeal to those seeking a 'medical' solution, without putting off vapers who are not seeking 'treatment'. However, it seems likely that some smokers may feel more confident about accessing vape shops and using e-cigarettes if they know that evidence- 
based support is available, and therefore that providing support may enhance vape shop profitability.

Among staff and customers who were supportive of an in-store smoking cessation intervention, most felt that the best way to deliver this type of service would be via a trained member of existing staff, although our data did not provide sufficient granularity to gain a comprehensive understanding of the type of advice and mode of delivery that might be appropriate and acceptable. Whether offering help to smokers to transition more effectively from tobacco to electronic cigarettes represents a commercial opportunity to vape shops, by helping to generate new customers; and whether this same commercial interest might then inhibit the promotion of complete cessation of vaping, remains to be seen.

\section{Conclusions}

The majority of vape shop customers are vapers who have quit smoking. Vape shop staff play a central role in providing customers with product information, and many provide smoking cessation advice. There is a need for clear and easily accessible information on the health effects and effectiveness of e-cigarettes for smoking cessation, to ensure that vape shop staff provide customers with accurate information on their products. Further research is needed to investigate the potential for smoking cessation interventions in vape shops, including the extent to which this type of intervention would appeal to non-vapers and how and by whom it would best be delivered.

\section{Additional files}

Additional file 1: Shop questionnaire. (DOC $321 \mathrm{~kb}$ )

Additional file 2: Customer questionnaire. (DOC $413 \mathrm{~kb}$ )

\section{Funding}

This work was supported by Cancer Research UK [C4027/A20493]. TL, MB, SL and JB are members of the UK Centre for Tobacco and Alcohol, a UKCRC Public Health Research: Centre of Excellence. Funding to the UKCTAS from the British Heart Foundation, Cancer Research UK, the Economic and Social Research Council, the Medical Research Council and the National Institute of Health Research, under the auspices of the UK Clinical Research Collaboration, is gratefully acknowledged.

\section{Availability of data and materials}

The datasets generated and/or analysed during the current study are not publicly available due to ongoing work on the overarching study but are available from the corresponding author on reasonable request.

\section{Authors' contributions}

$T L, M B, J B$ and $S L$ designed the study. JP collected the study data, conducted the initial analysis and wrote the first draft of the findings. $T L$ conducted further analysis and drafted the rest of the manuscript. MB, JB and SL edited the manuscript. All authors read and approved the final manuscript.
Ethics approval and consent to participate

Ethical approval for this study was granted by the University of Nottingham Faculty of Medicine and Health Sciences Ethics committee (REF D15092015 SoM EPH). Consent was implied by completion of the questionnaire.

\section{Competing interests}

The authors declare that they have no competing interests.

\section{Publisher's Note}

Springer Nature remains neutral with regard to jurisdictional claims in published maps and institutional affiliations.

Received: 25 September 2017 Accepted: 16 April 2018

Published online: 23 April 2018

\section{References}

1. McNeill A, Brose L, Calder R, Hitchman S, Hajek P, McRobbie H. E-cigarettes: an evidence update. A report commissioned by Public Health England. 2015. https://www.gov.uk/government/publications/e-cigarettes-anevidence-update. [Accessed 18 April 2018]

2. Royal College of Physicians. Nicotine without smoke: tobacco harm reduction. London: RCP; 2016.

3. Hartmann-Boyce J, McRobbie H, Bullen C, Begh R, Stead L, Hajek P. Electronic cigarettes for smoking cessation (review). Cochrane Database Syst Rev. 2016; Issue 9. Art. No.: CD010216. https://doi.org/10.1002/14651858. CD010216.pub3.

4. Malas M, van der Tempel J, Schwartz R, Minichiello A, Lightfoot C, Noormohamed A, Andrews J, Zawertailo L, Ferrence R. Electronic cigarettes for smoking cessation: a systematic review. Nicotine and Tobacco Research. 2016;18:1926-36.

5. Beard E, West R, Michie S, Brown J. Association between electronic cigarette use and changes in quit attempts, success of quit attempts, use of smoking cessation pharmacotherapy, and use of stop smoking services in England: time series analysis of population trends. BMJ. 2016;354:14645.

6. Brown J, Beard E, Kotz D, Michie S, West R. Real-world effectiveness of ecigarettes when used to aid smoking cessation: a cross-sectional population study. Addiction. 2014;109:1531-40.

7. West R, Beard E. And Brown J. Trends in electronic cigarette use in England Available from http://www.smokinginengland.info/latest-statistics/. Accessed 08/06/17

8. Felsted A, Robinson D: Ecigarette shops lead high streets' transformation. In Financial Times; 15th August 2014.

9. Anderson E: Britain really is a nation of shopkeepers: running a shop named as dream career. In The Telegraph; 9th December 2014.

10. Targeting RSPH. The supply and sale of e-cigarettes to smokers. Royal Society for. Public Health. 2017. Available from https://www.rsph.org.uk/ asset/0720985A\%2DCC1F\%2D49E5\%2D8C78CD061ACCC641/; Accessed 13 Apr 2017

11. Sussman S, Garcia R, Boley Cruz T, Baezconde-Garbanati L, Pentz M, Unger J. Consumers' perceptions of vape shops in Southern California: an analysis of online yelp reviews. Tob Induc Dis. 2014;12(1):22

12. Allem J-P, Unger J, Garcia R, Baezconde-Garbanati L, Sussman S. Tobacco attitudes and behaviors of vape shop retailers in Los Angeles. American Journal of Health Behaviour. 2015;39:794-8.

13. Cheney M, Gowin M, Franklin Wann T. Vapor store owner beliefs and messages to customers. Nicotine and Tobacco Research. 2015;18:694-9.

14. Cheney M, Gowin M, Wann T. Marketing practices of vapor store owners. Am J Public Health. 2015;105

15. Nayak P, Kemp C, Redmon P. A qualitative study of vape shop Operators' perceptions of risks and benefits of E-cigarette use and attitude toward their potential regulation by the US Food and Drug Administration, Florida, Georgia, South Carolina, or North Carolina, 2015. Prev Chronic Dis. 2016;13: 160071.

16. Polosa R, Caponnetto P, Cibella F, Le-Houezec J. Quit and smoking reduction rates in vape shop consumers: a prospective 12-month survey. Int J Environ Res Public Health. 2015;12:3428-38.

17. Sussman SA, Garcia J-P, Jocelyn UJB, Boley Cruz T, Garcia R, BaezcondeGarbanati L. Who walks into vape shops in Southern California?: a naturalistic observation of customers. Tob Induc Dis. 2016;14:18. 
18. Tackett A, Lechner W, Meier E, Grant D, Driskill L, Tahirkheli N, Wagener T. Biochemically verified smoking cessation and vaping beliefs among vape store customers. Addiction. 2015;11:868-74.

19. Hart J, Walker K, Sears C, Lee A, Smith C, Siu A, Keith R, Ridner S. Vape Shop Employees: Public Health Advocates? Tob Prev and Cessat. 2016;2(Suppl):10.

20. Lechner W, Tackett A, Grant D, Tahirkheli N, Driskill L, Wagener T. Effects of duration of electronic cigarette use. Nicotine Tob Res. 2015;17:180-5.

21. Tsai J, Bluthenthal R, Allem J-P, Garcia R, Garcia J, Unger J, Baezconde-Garbanti L, Sussman S: Vape shop retailers' perceptions of their customers, products and services: A content analysis. Tob Prev and Cessat. 2016;2(Suppl):3.

22. Burbank A, Thrul J, Ling P. A Pilot Study of Retail 'Vape Shops' in the San Francisco Bay Area. Tob Prev and Cessat. 2016;2(Suppl):6

23. Garcia R, Allem J, Baezconde-Garbanati, Unger J, Sussman S. Employee and customer handling of nicotine-containing e-liquids in vape shops. Tob Prev and Cessat. 2016:2(Suppl):10.

24. Sears C, Hart J, Walker K, Lee A, Keith R, Ridner S. A Dollars and "Sense" Exploration of Vape Shop Spending and E-cigarette Use. Tob Prev and Cessat. 2016;2(Suppl):10.

25. Wagener T, Shaikh R, Meier E, Tackett A, Tahirkheli N, Leavens E, Driskill L. Examining the Smoking and Vaping Behaviors and Preferences of Vape Shop Customers. Tob Prev and Cessat. 2016;2(Suppl):5.

26. Ward E, Cox S, Dawkins L, Jakes S, Holland R, Notley C. A qualitative exploration of the role of vape shop environments in supporting smoking abstinence. Int J Environ Res Public Health. 2018; 9;15(2). pii: E297.

27. eCig Directory. Available at: http://ecigdirectory.co.uk/ [Accessed 02/12/15].

28. Directive 2014/40/EU of the European Parliament and the Council on the approximation of the laws, regulations and administrative provisions of the Member States concerning the manufacture, presentation and sale of tobacco and related products and repealing Directive 2001/37/EC.

29. ASH. Use of electronic cigarettes (vapourisers) among adults in Great Britain. Action on Smoking and Health. 2017. Available from http://ash.org.uk/ information-and-resources/fact-sheets/use-of-e-cigarettes-among-adults-ingreat-britain-2017/. [Accessed 18 Apr 2018].

30. Liber A, Drope J, Stoklosa M. Combustible cigarettes cost less to use than e-cigarettes: global evidence and tax policy implications. Tob Control. 2017;26:158-63.

31. European Commission. Excise Duty Tables: Part III - Manufactured Tobacco. 2017. Available from https:/ec.europa.eu/taxation_customs/sites/taxation/ files/resources/documents/taxation/excise_duties/tobacco_products/rates/ excise_duties-part_iii_tobacco_en.pdf [Accessed 13 Feb 2018].

32. Belvin C, Britton J, Holmes J, Langley T. Parental smoking and child poverty in the UK: an analysis of national survey data. BMC Public Health. 2015;15

33. Farrimond H. A typology of vaping: identifying differing beliefs, motivations for use, identity and political interest amongst e-cigarette users. Int J Drug Policy. 2017:48:81-90.

34. Morphett K, Carter A, Hall W, Gartner C. Medicalisation, smoking and ecigarettes: evidence and implications. Tob Control. 2017;26:e134-e139.

Ready to submit your research? Choose BMC and benefit from:

- fast, convenient online submission

- thorough peer review by experienced researchers in your field

- rapid publication on acceptance

- support for research data, including large and complex data types

- gold Open Access which fosters wider collaboration and increased citations

- maximum visibility for your research: over $100 \mathrm{M}$ website views per year

At BMC, research is always in progress.

Learn more biomedcentral.com/submissions 